\title{
Correction to: Genetic diversity and reproductive ecology of the sage-leaved rockrose, Cistus salviifolius L., in the Swiss Alps
}

\author{
Marco Moretti ( - Paolo Caretti - Anya Bricalli · Marco Andrello
}

Published online: 5 April 2020

(C) Springer Nature B.V. 2020

Correction to: Plant Ecol.

https://doi.org/10.1007/s11258-020-01013-4

Figure 1 has been published incorrectly in the original article. The correct version of Fig. 1 is provided in this correction.

The original article can be found online at https:// doi.org/10.1007/s11258-020-01013-4.

Communicated by Marjana Westergren.

M. Moretti $(\square) \cdot$ P. Caretti · A. Bricalli

Biodiversity and Conservation Ecology, Swiss Federal

Research Institute WSL, 8903 Birmensdorf, Switzerland

e-mail: marco.moretti@wsl.ch

P. Caretti

IBSA Institut Biochimique SA, 6926 Montagnola,

Switzerland

\section{A. Bricalli}

Dipartimento del territorio, Ufficio Natura E Paesaggio,

6501 Bellinzona, Switzerland

M. Andrello

MARBEC, Univ Montpellier, CNRS, Ifremer, IRD,

34200 Sète, France 


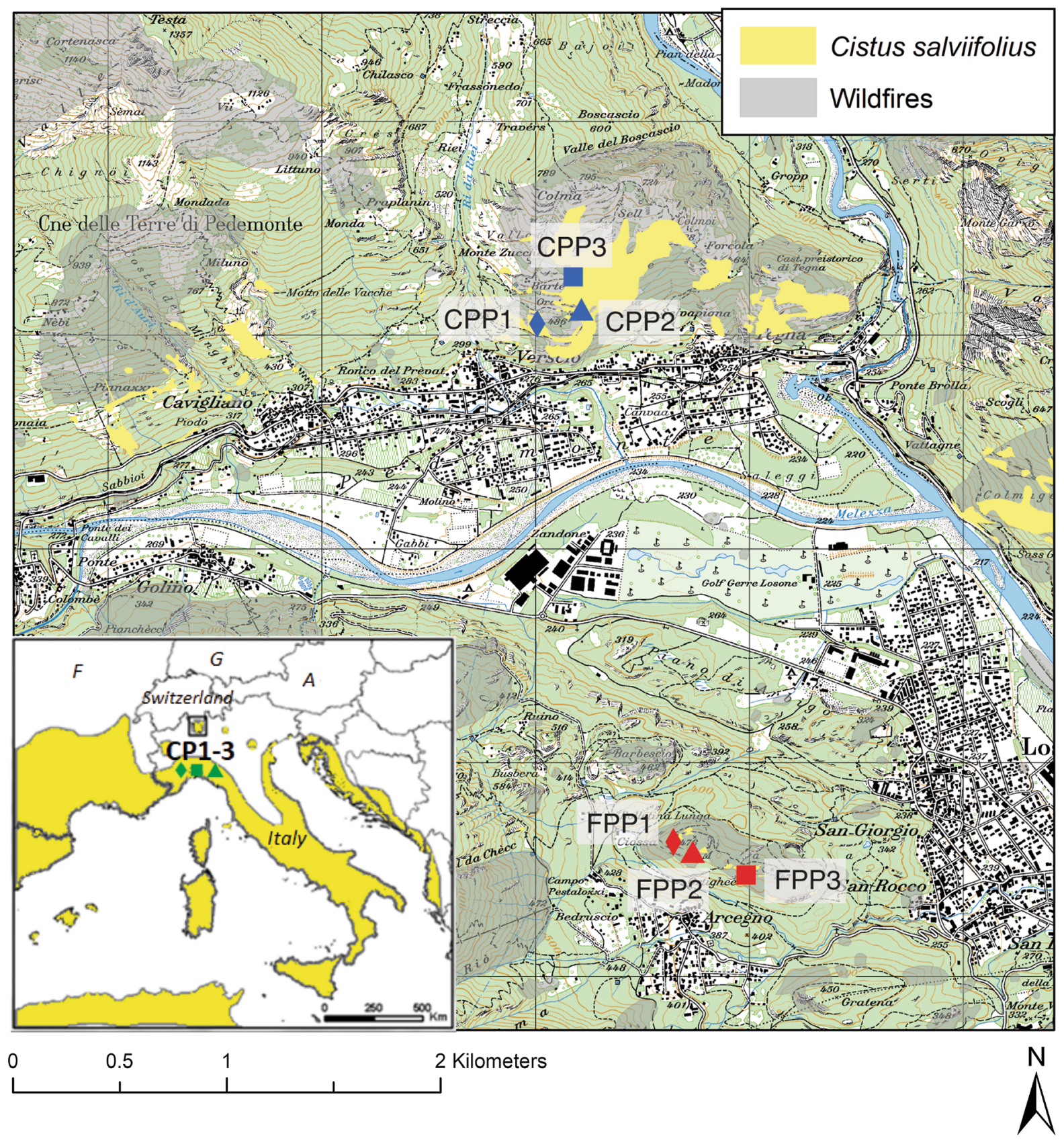

Fig. 1 Distribution maps of Cistus salviifolius (yellow area) in Southern Europe and the location of the three investigated populations: connected peripheral population CPP and fragmented peripheral population FPP at the Northern range margin in the Alps (Canton of Ticino, Switzerland,) and in the range core population $\mathrm{CP}$ in the Mediterranean (Genoa, Liguria, Italy).
The colored symbols indicates the three distinct sites per populations investigated during the study, i.e., $\mathrm{CPP}_{1-3}$ (blue color), $\mathrm{FPP}_{1-3}$ (red color), $\mathrm{CP}_{1-3}$ (green color), respectively. Within each sites data were sampled in sampling plots (not shown)

Publisher's Note Springer Nature remains neutral with regard to jurisdictional claims in published maps and institutional affiliations. 